\title{
Reading Models in Foreign Language Teaching
}

\author{
Marto Redondo \\ Universidad de Castilla-La Mancha
}

\begin{abstract}
Reading continues to be essential nowadays in spite of the audiovisual media. Thus, the availability of a pattern to master the mental processes activated when reading would be a panacea, but there is no such a unique reading model. Conversely, the ones devised up to now are partial and incomplete, as the authors themselves declare. This is why psychologists and linguists do not stop researching to find formulae which account for the mental processes taking part in reading as well as how they perform to achieve meaning from the written discourse.

This paper tries to pinpoint the main features of the most representative reading models of the last three decades, underlines as much as it concerns to the L2 reading process and shows how the various components of the reading models have evolved to line themselves up under the interactive paradigm. Moreover, it also suggests a psycho-pragmatic model of reading for learners of English as a second language made up of psycho-pragmatic, interactive and pedagogical elements.
\end{abstract}

\section{The definition of 'model'}

In the cultural system we live in, we are almost unaware of the fact that we learn to copy behavioural models because of their ingenuity, attractiveness, moral quality or some other positive aspect of these models (ironically, a model may also provide an example of what should not be done). They may have a significant influence on one's behaviour when 
dealing with everyday situations, at least in the short term, irrespective of the extent to which they are followed through, or whether they are rejected and/or substituted for alternative models.

In much the same way, science produces and uses models in order to provide a framework within which research problems can be solved. For this reason, linguistic research tends to build models so that one may deal with, represent, define and justify, in other words, study linguistic data in various circumstances.

In linguistics, a model is a systematic and operative way of explaining certain aspects of language to show its structure or function.

Models provide samples of language which represent its basic structure in order to understand it better (Alcaraz 37). To make this organised and interrelated simplification, a knowledge of the elements of the structure is necessary as well as the position that the simplification occupies in the body of the theory, description or explanation, extracting and formalising the areas which are subject to analysis.

In the field of linguistics, there are various meanings of the term 'model', although they have many points in common. These are: paradigmatic or investigative, theoretical or interpreting a theory, hypothetical or representing well-established hypotheses, descriptive, general framework or following the criteria of another science, and macromodel or equivalent to the epistemological system (Alcaraz, op. cit.).

The theoretical and hypothetical models are probably the most commonly used in linguistics, where models are precise, functional, operative and plausible schemes. These models are based on the general formulation of a theory or hypothesis, which can be interpreted (Black 1962). The model relating to the linguistic aspect of L2 teaching and learning could belong to either of these categories. It emphasises certain methods by providing students with models to imitate, such as the audio-oral method which aims to achieve a standard of pronunciation which is as near as possible to that of a native speaker.

Therefore, taking into account the effectiveness of using reading models for learning, I will now go on to discuss several aspects of these models.

\section{The history of reading models}

The concept of reading has changed with time as the nature of education has evolved. Nowadays a typical reader would be someone able to process a written text in silence to obtain, use and analyse information or to entertain themselves. On the contrary, during the 18 th and 19th centuries, reading meant the reciting aloud of various well-known religious texts, such as prayers or extracts from the Bible (Darnton 1984).

However, few adults at that time were able to read, and, for that matter, recite aloud, and among them, only a small proportion was able to understand a non familiar written extract (Just \& Carpenter 1987). Take, for instance, the familiar scene of taking part in church mass by reading aloud or reciting by heart, in Latin, without being able to undertand most of the written texts. Consequently, my view is that if the reading model does scientifically exist, it will also have evolved in order to adapt itself to the prototypical reader of the time. 
In fact, it has been little more than a century since research into reading models began. Furthermore, if we exclude Javal's first essay (1879) on the movements of the eyes, and Cattell's (1886) on the amount of time taken from initial visualization to the naming of objects, the development of consistent reading models, that is, models describing the whole process from the moment when the eye is facing the page until the reader experiences understanding, began only 35 years ago.

With regard to the relative lack of activity, until recently, in this area, is it possible to ask ourselves why researchers failed to take an interest in this field? Did they lack the motivation to tackle all the aspects of the reading process, or was the delay due to a lack of scientific prototypes which would have allowed the induction of reading models? The reason is simply that the tradition of conceptualising knowledge and theory in explicit reading models was not established until the mid-1950s to 60s (Samuels \& Kamil 22).

My personal view is that both the evolution of linguistics and psychological studies of the mental processes such as Aspects of the Theory of Syntax (1965) or Language and Mind (1968) by Chomsky promoted scientific interest in the research into reading. In this way, the psycholinguistic works of Goodman $(1966,1976,1970)$ and Smith (1971) created the main theoretical background for the way in which reading models function, thus providing a substantial body of empirical evidence for the term 'model'.

\section{Chronology of formal models}

1964: Carroll devises a definition of reading based on a unidirectional diagram; beginning with visual stimulus and through a recoding of oral language, his research gives rise to significant findings. The model is merely illustrative, non defining and leaves many stages without precise specifications.

1969: Ruddell, in contrast, develops a model system that provides a huge amount of detail about the stages and constituent processes of the reading process.

1970: Goodman announces a model which gives rise to a formula in which its components and stages are expressed. This formula would be able to explain and predict reading behaviour. The model, which he completed with a flowchart, was introduced in 1966 and was improved several times until 1988.

Almost all of Goodman's works set out to show the readers' preference to rely on meaning as opposed to the graphic and morpho-phonemic clues available in the written text.

Compared with both earlier and subsequent authors, it is important to highlight the great impact his model has had on ideas about the teaching of reading. In fact, it has served as the basis of many activities in teaching handbooks. It has become known as the psycholinguistic approach to reading.

1971: Smith also describes his model as being psycholinguistic, but critics claim that it is less a model than a description of the linguistic and cognitive processes which all reading models should take into account. Like Goodnıan, he distinguishes whether the identification of meaning is immediate or thought through and whether it lies in the procedural character or in the basic graphic automatism of the language. His contribution 
offers more than simply providing a different model; it explains how the inherent redundancy in any language level (features of the letters, words, sentences and discourse) gives the reader great flexibility in organizing his resources to derive meaning from the text he has before him.

1972: Gough bases his reading model on the effect that the processing of information produces on the various mental processes. He displays contradictions, since his model presupposes that all the letters in the visual field have to be processed individually, before the reader can assign a meaning to any group of them. He has provoked as much controversy on the basic processes as Goodman has with his instrumental practice theories.

1974-77: LaBerge \& Samuels emphasise the automatism of the components of the processes with their model.

1977: Rumelhart, with interactive model, highlights that flexible processing and multiple sources of information depend on contextual circumstances. He provides convincing evidence that the perspective of processing information lies in the field of reading. He reinforces the previous works of LaBerge \& Samuels. In 1981, together with $\mathrm{McClelland}$, he reelaborates it and initiates research into the recognition of the word.

1977-1978: Carver puts forward a model which is reminiscent of Gough's due to his emphasis on letters - sounds - meanings and of Holmes's (1953) and Singer's (1983), because of his interest in the empirical evaluation of all aspects of the model.

1978: Kintsch and van Dijk elaborate a model which, given the multiplicity of the processes that sometimes occur in parallel and at other times in sequence, interprets understanding as also excluding identification of the word, in contrast to the majority of preceding models which appear to emphasise this idea.

1980-1984: Stanovich develops an interesting extension of Rumelhart's model, integrating serial and interactive features and calling it 'compensatory'.

1980-1987: Just \& Carpenter build a model that explains understanding of reading processes based on studies of eye movement.

1983: Taylor \& Taylor speak about the model of bilateral cooperation, thereby complementing features of Rumelhart and Stanovich's models with neurolinguistic contributions. They devise strategies that work in parallel for various levels of textual information. In the process, mechanisms of fast and slow processing are activated, according to the needs of the reader and the difficulties involved in the reading task or text.

\section{Principal categories}

With regard to this brief list and the latest significant contributions, reading models can be classified as being psycholinguistic, serial, interactive or compensatory, depending on the functional relationship assigned to the different processing levels concurrent in the reading process. Whilst all being in use, they are also continually subject to revision by their authors. Moreover, although those which are strictly speaking serial models tend to be underestimated, they are still extremely valuable. In fact, they are essential in order to fully understand the comprehension process, providing the key to understanding the 
information process of the bottom-up model, and, in addition, they serve as a contrastive reference with regard to top-down models.

\subsection{Goodman's psycholinguistic model (1970-88)}

The factors that play a part in the reading process are optical, perceptual, syntactic and meaning. Each fuses with the following one to be able to arrive at the meaning as soon as possible, which is constantly the reader's goal (figure 1).

\section{FACTORS OF THE READING PROCESS IN GOODMAN`S MODEL}

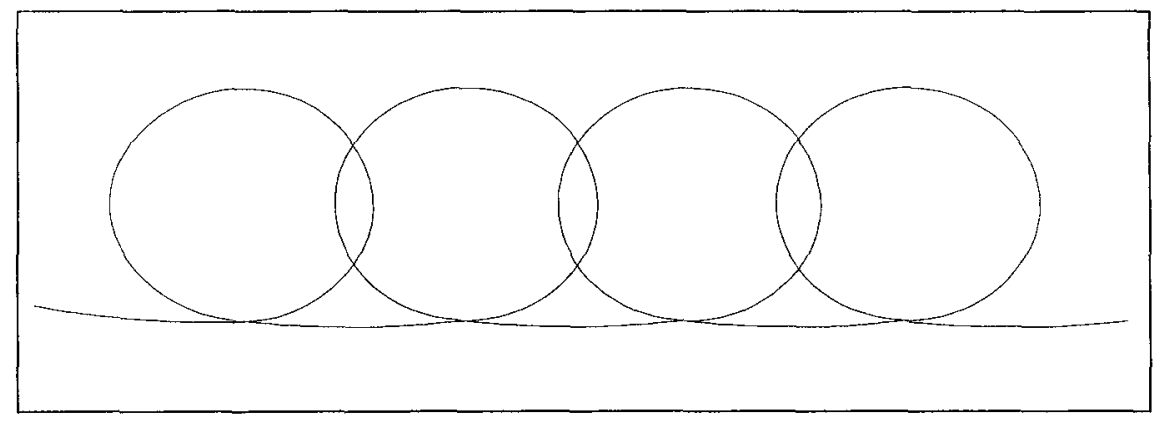

Figure 1

From a psycholinguistic point of view, that is, interdisciplinary science concerned with how language and thought are interrelated, the information that the model uses comes mainly from the analysis of oral errors ('miscue' analysis) and is characterised by belonging to the spatial symbols (sounds - letters), to the arbitrary structure of language (grammar and syntax) and to the semantic system of memory (concepts and conceptual structures).

\section{- Process}

The reader follows a constant attention cycle in the building of meaning through the following steps:

Starting and recognition. The brain identifies the graphic sample in the visual field and starts reading. If there are any interruptions (graphs, illustrations, etc.), the phase will start again.

Prediction. The brain is constantly anticipating and predicting because it is always searching for order and meaning in the sensorial stimuli.

Confirmation. If the brain is predicting, it also has to verify its predictions. Therefore with every new stimulus, it checks whether or not its expectations were correct.

Correction. The brain restarts processing when it discovers inconsistencies or its predictions are not correct. 
Ending. The brain will cease the reading activity for the following reasons: the text ends, the activity is not productive, little meaning is derived from the text, the meaning does not interest the reader or is not appropriate for the purpose intended, etc. In any case, the ending stage is an option open at any moment.

Although the steps have an intrinsic sequence, by means of which prediction precedes confirmation and confirmation precedes correction, the same information can be used to confirm previous predictions, and to create new ones.

During the process, short-circuits can appear, which impedes being able to obtain a meaning when reading the text through. This is due to use of the wrong strategies, which are acquired by the individual or through poor teaching, such as spelling out unknown words to oneself, matching written and spoken codes without assigning them any meaning, recognising of deep and surface structures without getting the meaning, etc. The result is the acquisition of a fragmented meaning as opposed to the ideal of complete understanding.

\section{- Comments}

The model is based on an exhaustive collection of data which the author uses to support and evaluate it. Known as 'Reading as a psycholinguistic guessing game', it is characterised by its procedural preferences which allow the reader to rely on the structures of semantic and syntactic knowledge, minimising its dependence on graphics and sounds associated with it.

Readers do not need to use all the textual clues to achieve understanding; in fact, the better the prediction, the less textual' confirmation required (Goodman 164). According to this view, the meaning of written language is reconstructed by using the grapho-phonemic, syntactical and semantic systems of language. In short, then, the process followed by the reader is to:

- search for the most direct way to find meaning

- use strategies that reduce uncertainty

- select keys to interpretation

- use his conceptual and linguistic knowledge

Although Goodman (1981) refuses to class his model as being top-down, renown theoretical writers classify it as being conceptual, where higher level processes interact with lower ones and direct the flow of information across them. In this way, an L2 reader becomes an active partipant in the reading process, when he makes and confirms predictions, making use of his existing knowledge of the different linguistic levels (graphophonemic, syntactical and, above all, semantic).

The model does not prevent the reader from going from symbol to meaning through sound, but it admits that the intermediate stage of using sound can be eliminated when one has become perfectly familiar with the graphic/sound relationship or by means of the educational process.

Goodman uses the term 'decodification' to describe what the reader does when he turns a graphemic or phonemic element into meaning, as opposed to those who state that it is equivalent to translating graphemic into phonemic, which is called 'recodification' 
because both oral and written language are codes. In this way, the transformation can either be direct, from grapheme to meaning, or go through an intermediate stage, from grapheme to meaning through phonemes.

In short, Goodman's model is unique (infinite macro-model), psycholinguistic (interaction of language and thought), sociolinguistic (working in a social context) and global (it addresses every stage of the reading process).

\subsection{LaBerge \& Samuels's serial model (1974-77)}

\section{- Components}

The elements of the process are visual memory (visual traits, letters, syllables, words, group of words), phonological memory (sound of the syllables, words, group of words) and the semantic memory (meaning of words and of groups of words).

\section{- Process}

The reader activates the corresponding codes in order to recognize and link together the components and the field in a hierarchical pattern. Visual perception, the first level of processing, provides the base for the following one, the recognition of letters; this, in turn, is a base for the syllabic integration stage and so on, until the whole text is semantically processed (figure 2).

\section{LaBERGE \& SAMUELS's SERIAL MODEL}

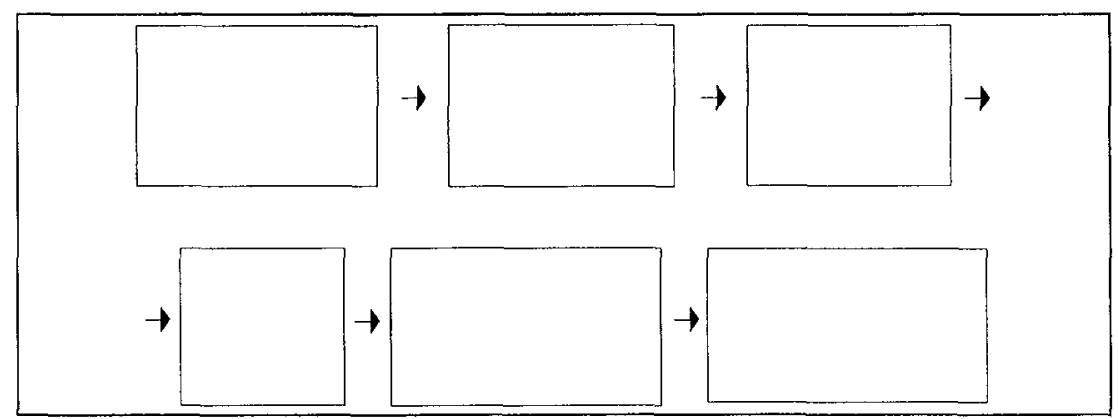

Figure 2

The components of each field are analytically processed from lower to higher levels in every component and field, that is, bottom-up and from left to right (figure 3 ), giving rise to automation when the processing of one or more of the components becomes clear for the reader. 


\section{L \& S'S REPRESENTATION OF THE ANALYTICAL BOTTOM-UP PROCESS}

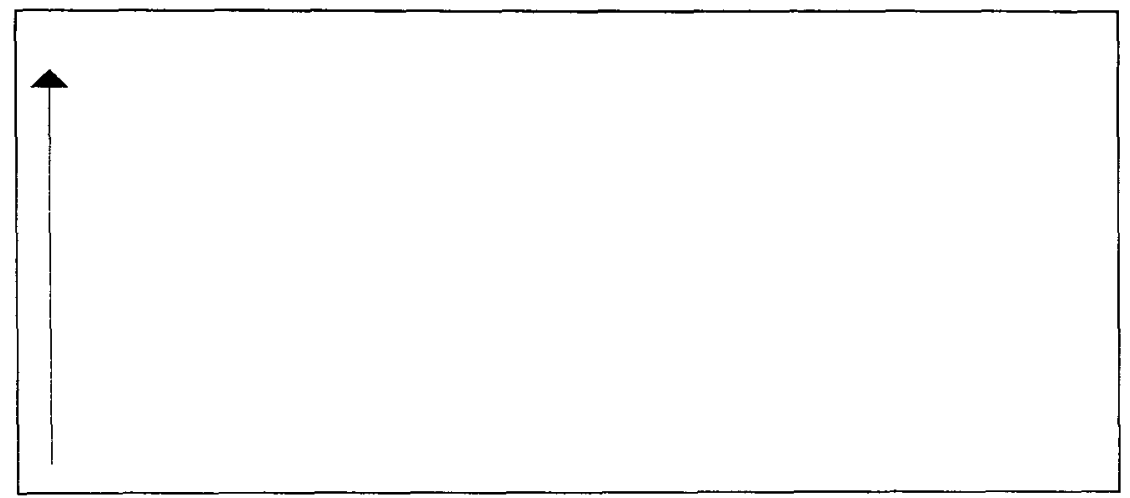

Figure 3

According to the diagram, the meaning is built upwards, without having a functional dependence in the opposite direction. Thus, the speed of processing the words would be unaffected by the syntactic or semantic processing.

The authors analyse in detail the sequential processes which take part in visual, phonological and semantic perception, assigning them different functions. In the first one, they join together the graphic and letter codes, syllables, words and groups of words; in the second, the phonetic codes of syllables, words and groups of words; in the third, the codes of word meaning and groups of words.

\section{- Comments}

The exacting nature of the structural elements does not imply that the model is inflexible; on the contrary, depending on the texts and the reading skills of the individual, the linking process can vary in each case and cause jumps (automatisms) if the reader does not require these elements during the activity of mental processing.

In my view, the expert reader tends to skip the visual perceptive processes as soon as possible, although in reality they serve as an intermediate stage in many circumstances. For example, if the reader finds an unknown word he may need to activate the visual and phonological codification stages before reaching the semantic level.

In conclusion, LaBerge and Samuels state that learning the reading skills is a process of automating the visual, phonologic and semantic levels. In this way, a beginner reader keeps his attention on the lower levels, but with practice the majority of these become automatic, thus freeing the attention and allowing for more intensive concentration on semantic and interpretative levels.

The model was revised by Samuels himself in 1977, admitting that the original linear conception would allow interactions between stages of different levels. This modification brings it nearer to the interactive types of model. 


\subsection{Rumelhart's and McClelland's interactive model (1977/81)}

\section{- Components}

Sources of orthographical, lexical, syntactic and semantic information. Mental synthesiser of mental processes and message centre (figure 4).

- Process

It emphasises flexible processing and multiple information sources, depending on contextual circumstances, showing that the perspective of the way information is processed lies in the field of reading.

The processing of the text and its final interpretation are influenced by orthographic, lexical, semantic and syntactic information. All these factors join together as a synthesiser of mental processes which, through the message centre, accepts, keeps and distributes information according to its needs.

The message centre has several functions. It stores information received in the shortterm memory; it opens up to the different sources for data analysis; and confirms, denies, takes out or adds to the hypothesis of the corresponding subject areas, according to the results of the analysis. The procedure keeps going until the 'supposed' right decision is reached (Rumelhart, 1977: 589-590, figure 4).

\section{RUMELHART's AND MCCLELLAND's INTERACTIVE MODEL}

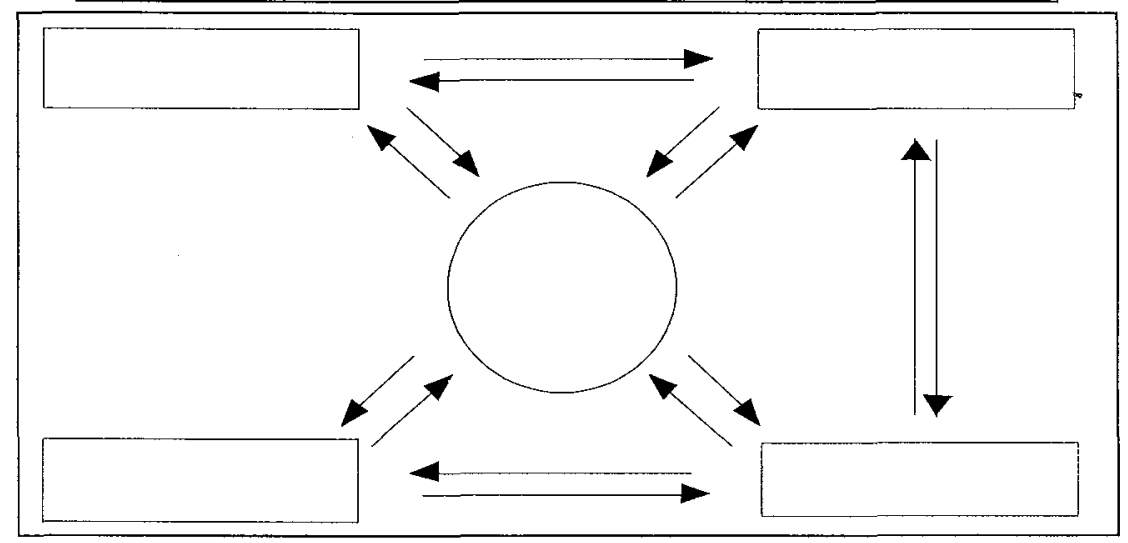

Figure 4

The message centre ensures that a bidirectional relationship is maintained between the levels. Although the high level processes in this model depend on the knowledge acquired at the lower levels, the first enables speed in recognition and assimilation of the second. Therefore the processing of information occurs in both directions, that is bottom-up and top-down. In this way, figure 2 above would become figure 5 below: 


\section{RUMELHART AND MCCLELLAND's BIDIRECTIONAL PROCESS}

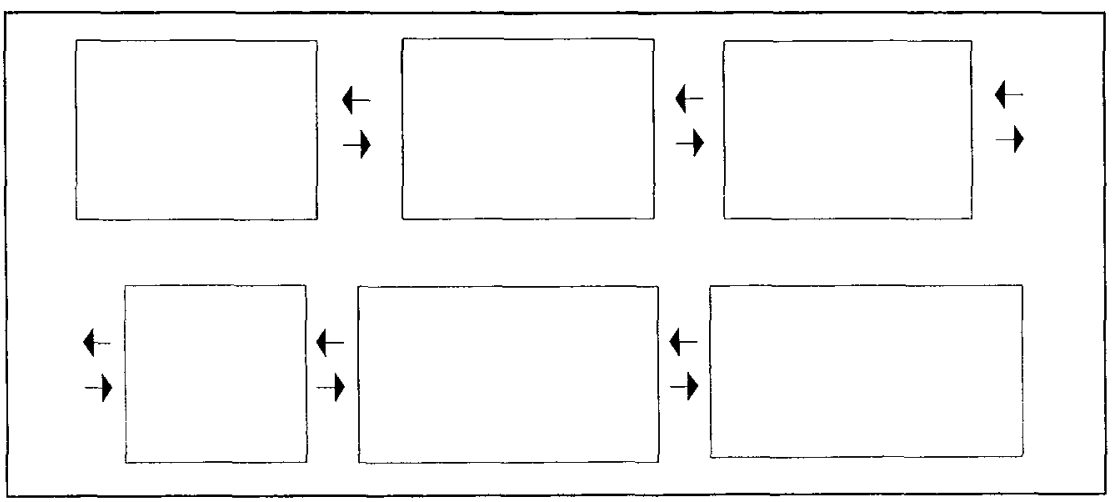

Figure 5

In short, the mind activates individual features (letters, groups of letters, context, syntax, semantics, topic, previous knowledge, etc.) to select the meaning and word comprehension. When the activation of different sources increases, the lexis which is not affected by any of the sources is blocked and only one or two words reach awareness level. The process is quicker than the conscious experience. The automatism of the processing allows concentration on comprehension more than on active selection or word prediction.

\section{- Comments}

This model was devised to overcome the deficiencies of linear models which transmit information in one direction only without allowing information from a higher level to affect that of a lower level. The authors indicate five factors of the reading process which can be explained by this mutual influence.

The first deals with the fact that more letters can be learnt in a period of time if they appear in a common word, eg. 'classroom', than if they are disordered and do not make a proper word, eg. 'mclosrsao', (Huey 1908/1968), or if you try to learn the letters of a nonsense word, but arranged in a conventional way, i.e. 'pertangle', compared with the same letters arranged in a non-conventional manner, eg. 'rtlnaeepg', (Miller, Bruner and Postman 1954). It shows that, although letter recognition is a typical lower level information process, some mechanism must be activated on letter perception to grasp both the lexis and the orthography contained in higher levels. It can also explain why we Spaniards, for instance, tend to be better and faster at learning languages with Latin roots rather than languages of Saxon origin.

The second refers to the syntactic effects on word perception. When we fail to recognise a word, there is a strong tendency to substitute it with another which maintains the same syntactical function in the sentence (Kolers 1970; Weber 1970). 
The third considers the influence that semantic knowledge exerts on word perception. Various experiments show that, compared with disordered words, i.e. 'dbrae, ttberu, rtodoc, usnres', word orders are more easily formed when they are semantically related, eg.'bread-butter, doctor-nurse', than if they are not, eg. 'bread-doctor, nurse-butter' (Meyer, Schvaneveldt and Ruddy 1975), or that the recognition of a word is faster if parts of the sentences in which it appears are given, rather than if the word is shown in isolation (Tulving and Gold 1963).

The fourth, refers to the way that ambiguity is minimised in the syntactic perception of words if we have the context in which they belong. In 'they are eating mushrooms', the issue of whether 'eating' refers to the action of eating, verbal function, or to a type of mushrooms', a noun attributive function, is deduced better in a wider context, such as 'What are these people doing? They are eating mushrooms' or 'What type of mushrooms are they? They are eating mushrooms'.

The fifth states that the interpretation of what we read depends on the context in which the segment of language is included. For example, if we interpret the word 'tree' in:

A number of operations may be carried out on trees. Two binary trees may be joined to an additional node, which becomes the root of a larger binary tree, with the original trees or subtrees. Trees have a number of applications in computing.

we would take the meaning as being in a computing context. On the other hand, in:

A number of operations may be carried out on trees. After cutting down, trees are usually pruned, peeled and left drying. Then they are taken to factories to build furniture, doors, windows or boxes.

the term refers to the tree as being a wood producer. The meaning, then, is not taken from the individual segment we are processing, but from the environment that surrounds it.

From all of this we can infer that orthographic, lexical, syntactic and semantic information affects our perceptions. In each case, higher level knowledge affects the analysis of the lower one. Therefore, all these sources of knowledge influence the processing and final interpretation of the text.

According to Rumelhart, this is how information from sources converges in the mind, where it is accepted, retained and allocated according to needs. The information received is temporarily stored, ready for use when required by one or more of the other sources. For example, lexical knowledge may require back-up information in order to check, spell or just for syntax. By means of this interaction, higher level stages can influence lower level ones.

\subsection{Stanovich's compensatory model (1980/84)}

\section{- Components}

These are the same as in the previous one, supplemented with a compensatory mechanism. 


\section{- Process}

For the serial models, the processing of reading tends to represent the flow of information in a series of discrete stages; at each stage, the input is transformed and the non- registered information goes to the next one to be transformed and re-coded again. The sequence of processing is, then, bottom-up, from the input of data up to codification at higher levels.

Due to lack of feedback, these models do not explain what sort of mental mechanism allows the further processing of the stages when a gap appears in a lower stage. This is why it is difficult to explain with these models, for example, the effects of context in the sentence or the role of possessing background knowledge of the subject, which are both variables that facilitate the recognition of words and their meaning.

Models in favour of top-down processing consider the reading process to be interactive. The reader simplifies textual information to check his hypothesis and predictions; reading is conceptually driven by the higher level stages, typically final processing stages, interacting with previous sequences for these operations. Moreover, high level stages seem to drive and direct the process by doing the most difficult work. Therefore, top-down models begin with hypothesis and predictions and try to verify them by moving down to the written stimuli, while bottom-up processes base the processing on an analysis of lower stimuli.

Both ideas have limitations. I have already mentioned some of these in connection with bottom-up procedures; with regard to top-down models, it can be said that if the reader does not have previous knowledge of the topic in a text, he will not be able to generate predictions; or that, even if someone is a good reader and able to generate them, if it takes longer to predict than generate words, he will opt for reading. Hence, though the beginning of reading can be explained by lower level word recognition, top-down models do not provide a precise description of behaviour involved in advanced reading.

Stanovich tries to bring in his interactive-compensatory model to solve this problem. A key concept in his theory is that "... a process at any level can compensate for deficiencies at any other level." (Stanovich 1980: 36). In this way, if there is a deficiency in a lower stage, the reader will try to compensate for it by means of higher level knowledge structures. For the poorer reader, who experiences difficulty in word recognition and in speed of reading, but with a good knowledge of the subject he is reading, top-down processing can provide him with the information he needs.

On the other hand, if the reader has little trouble in recognizing the words but lacks knowledge of the subject, he may find it easier to use bottom-up processing to help him. Stanovich states that the interactive models allow the synthesis of a norm based on the information which is simultaneously received from various sources of knowledge. The compensatory assumption states that a lack of any type of knowledge leads to a dependence on the others, without considering which level they belong to in the hierarchy of processing (Grabe 1988). Therefore his model is interactive in that any stage, independently of its position in the system, can communicate with another; and it is compensatory because any reader is able to make use of the knowledge source which is the best developed for his purposes, when other sources which are less familiar to him are more difficult to use, even if they are normally the more common ones. 
In addition, it incorporates the concept of the initiation of the activation process by means of which, when reading, it is possible to have words which are already in one's mind automatically at one's disposal when they have a very close semantic relationship. This sort of activation, since it is automatic, does not require any attention, therefore it is a contextual factor that the reader does not control.

\section{- Comments}

In short, I think that Stanovich's contribution to reading models explains, from a theoretical point of view, the apparent anomaly that in certain circumstances, some lower level readers are more sensitive to textual difficulties than good readers. If the determinants were, for instance, a poor source of lexical and/or orthographic knowledge as opposed to syntax and semantics, the reason for good readers being less aware of contextual effects could be due to having less knowledge about sources of lower level processing.

\subsection{Just and Carpenter's eye movement model (1983-1987)}

\section{- Components}

These authors take the following elements into account in the description of their model:

a) Patterns of eye movement.

b) A computer program to measure reading time.

c) Statistical techniques of multiple regression, where the dependent variable is the length of looking time and the independent one is the consideration of the number of syllables, frequency, semantic value, integrative value, etc. (up to seventeen).

d) The presuppositions of immediacy (the reader tries to extract the most out of each word, interpreting it immediately, though at times they are only provisional guesses) and the one of the mind-eye (the eye focuses attention on a word until it is completely processed, so that the duration of the looking process reflects the time taken by the cognitive processes. Only the words projected in the fovic area by means of the retina are processed; the words reflected in the corner of the eye are not semantically processed).

e) Long term memory: this retains the reader's general knowledge about orthography, phonology, syntax, semantics, discourse structures, situational schemata, etc.

f) Short term memory: this has a limited capacity, it retains the representations activated during the execution of the operations involved in the reading process.

\section{- Process}

Readers are exposed to a text and stop at every word with a meaning, they seldom skip over words. The length of looking time is very variable because it is sensitive to the underlying cognitive processes.

Due to the limitations of the short term memory, it processes the information in cycles. Each cycle begins with a visual movement to the next word of the text and this continues while looking is focused, which is the amount of time necessary to process the word in all the possible levels. These levels are: 
a) Word coding and lexical access.

b) Syntactic coding and semantic determination.

c) Integration of clauses.

d) Construction of sentences.

- Comments

The authors construct a wide-ranging model that overcomes some of the limitations in Rumelhart's model and shows that the duration of time spent looking at the words of a text is extremely sensitive to linguistic parameters of several levels of processing.

The computer automatically registers the amount of time spent reading long or new words, or those used to expand linguistic units, integrative sentences in paragraphs, or paragraphs in a discourse, and it is shown to be longer than the time taken for words that are not displayed by these characteristics. In particular, the ending words of both clauses and paragraphs and those appearing for the first time are the ones that require a larger amount of processing and looking time.

The seventeen independent variables used, corresponding to all the levels of processing, explain $72 \%$ of the variance of the duration of looking times. Some critics say that many of the variables are interrelated and that it is not possible to separate their effects.

With a very new methodology and background, Just and Carpenter produce their model by using a computer program, READER, in their 1987 publication. This model is able to operate at the described processing levels and mime the patterns of eye movements.

\section{Criteria for evaluating reading models}

Although we do not have a pattern at our disposal to evaluate them, four parameters can be identified to classify current reading models. These are:

a) The scientific paradigm in which they appear,

b) Their defining categories,

c) The experimental factors from which they come, and

d) How well they match the features of a good model.

\subsection{The influence of science}

The scientific philosophy at the time when they appear is essential in the configuration of the model.

Those which appeared prior to the 60 s are said to be behaviourist, and they try to describe how stimuli and answers are associated (the printed text and the response to its recognition), and do not pay much attention to the reaction of the individual's mind during this process; in contrast, those which appeared after the $60 \mathrm{~s}$ are concerned with the mental processes (memory, attention, etc.) that play a part in the reading process, according to cognitive psychology. 
However, classification remains difficult. The mentalist character of the models exposed here sometimes shows signs of previous scientific views such as in the case of LaBerge and Samuels's serial-analytical model, and at other times, displays the advances of the new cognitive paradigm of computational processing of information, as in the case of Just and Carpenter's 'READER'.

\subsection{Defining categories}

There is no general agreement regarding the theoretical categories that define a reading model. DeBeaugrande (1981) has mentioned up to sixteen which describe them; Moshental (1984) adds environmental factors which help to define every specification of the model more precisely. Some of the more salient categorizations would be: the type of processing (serial/parallel, bottom-up, top-down), memory (abstract, constructive, reconstructive, operative, long term), socio-politic-cultural factors, the contribution of statistics and logic, the areas that the model refers to, etc.

\subsection{Underlying experimental factors}

There are at least four main spheres likely to have an influence on the information of the experimental phase. These are: age and knowledge of the individuals concerned, activities they wish to accomplish, materials they use and the context of the study (class, type of school, laboratory, etc.). A change in any of them can alter the results of the study and, consequently, the author's view of the process.

Therefore, their range constitutes a key factor in the assessment process. Questions to be answered are:

- Does the model describe initial reading as much as fluent reading?

- Does the description of the model prove to be useful both for multiple tasks and aims?

- Does the model describe the comprehension of words in the comprehensive model?

- Is it valid for different materials and contexts?, etc.

It is inferred from the possible answers that none of the current models can satisfy all these requirements; so it is necessary to undertake a careful study of each one and weigh up their potential.

\subsection{Conditions of a good model}

We can identify three conditions:
a) That they are able to summarise the past,
b) Have an understanding of the present, and
c) Can predict the future. 
A model satisfies the first condition when it synthesises large amounts of relevant information produced about it in the past.

The second condition requires that in spite of the complexity that usually accompanies any phenomenon, the model aids understanding by eliminating secondary aspects and showing clearly how its basic components interrelate and function.

It fulfils the third one if it enables the formulation of verifiable hypotheses. Throughout history, there have been models that have failed because they did not go beyond previous hypotheses, eg. that the earth was believed to be flat and that it was at the centre of the universe. Checking the models will help us to eliminate useless information and keep valid items for current and future investigations.

These circumstances indicate that most reading models are subject to constant revision, as stated for some of the cases already mentioned; it is frequent that the authors themselves, in succesive studies, have modified some of their previous views. For example, LaBerge and Samuels, who produced a strictly linear model at the beginning, where the higher level stages were unable to influence lower ones, admit in their 1984 publication that interaction between the different stages of their model is, in fact, possible.

\section{Interaction in reading models}

In studies of reading, the word 'interactive' proliferates to the point that it is common in almost all of them nowadays. At times it is used for the mental processes that occur in the reader's brain, or else for the interaction of elements that make up the text, and at other times it describes the different reading models, as already stated.

With regard to the reader's mind, reading interaction is the process of combining the information in the text with the information that the reader already possesses (Widdowson 1979). According to this view, reading is more than a process of extracting data, it activates knowledge in the human brain to improve and expand it. Thus reading becomes a type of dialogue between reader and text. This view, shared by many other writers such as Carrell and Eisterhold (1983), presents two main problems in my view: excessive dependance by the reader on the processing of the text and the context.

Independently from the interaction between text and reader, the constituent elements of the text give rise to the different genres and subgenres of written discourse. Such elements are variables or linguistic forms which concur or interact simultaneously. They are used by the writer with the aim of producing the desired function according to the pragmatic function of the discourse. The clarification of the complexity of these relationships is the target of investigations such as Biber's (1986) and Grabe's (1988).

Interaction in reading models assumes that the skills of any other level are permanently available to process and interpret the various components of the text (graphic characteristics, letters, words, phrases, sentences, cohesion, paragraph structure, discourse topic, inference and background knowledge).

Interactive models incorporate the idea of reading as an interdependent mental process, whilst at the same time enabling fast and accurate recognition of features of letters and words, extensive activation of lexical items and the concept of automation when 
processing, without this being dependent on calling on the attention for primary recognition of the linguistic units.

There are no models which are exclusively interactive; all of them include serial processing with interaction between each of their stages. In fact, some serial factors, such as the higher speed of lexical recognition than activation of contextual effects by better readers (Balota, Pollatsek and Rayner 1985), continue to be left unexplained by the conceptually driven top-down models, that is, the truly interactive ones.

Every interactive model, despite its contribution to the reading process and to generally recognized cognitive psychology, also has however, its own stereotypical category. All of them have aspects that have been dealt with inadequately, that is, gaps that have not been yet been filled, being therefore partial or imcomplete models. But their acceptance provides important results for dealing with reading in the $\mathrm{L} 2$ language, namely that:

(a) Interaction is common to all reading models as is the dominance of the higher level processes over the lower ones. How they interact exactly, that is, how this superiority affects the different processes (background knowledge, discourse topic, inference and schemata) is still an issue to be further researched and improved in future studies. In spite of this, we must not forget that interaction is not 'everything' in the reading process (Eskey, 1986).

(b) The fact that many lower level skills are basic factors of a good reading level, and are frequently clear to the reader, indicates that practical research into faster visual recognition, the extensive acquisition of lexis and better knowledge of syntactic structures, should continue to be an issue of interest in pedagogical research.

(c) It is necessary to be able to access a huge amount of vocabulary automatically and precisely; this can prove to be the biggest constraint for fluent reading in L2, particularly in academic reading.

(d) Some $L 2$ readers can, by using Stanovich's compensatory method, become excessively slow and text-dependent, due to lack of relevant schemata; others can compensate for this by over-inferring. Those who cannot process quickly and automatically can compensate by relying on words or predictions. But further insights are still needed to explain typical problems of the L2 student, such as the attachment to words or the unwillingness to predict meanings.

The development of one's capabilities can be more fruitful through attention to the process of the different stages in reading strategies. Chall (1983) shows five stages, the study of which could account for many problems of over-compensation observed in reading: pre-reading, initial reading or decodification, confirmation and fluency, reading to obtain/contrast information and reading to construct/reconstruct criteria. The interactive process begins in the third stage. The different types of processing of each one are 
particularly interesting and are worth being considered when researching reading skills of L2 students.

In conclusion, interactive reading models account for many aspects of understanding and widen our outlook, encouraging further investigation of intriguing questions, though it can be claimed that they do not provide all the answers we are looking for regarding the reading process.

\section{Pedagogical implications for $\mathrm{L} 2$ reading}

We have observed that the human brain activates psychological components when reading in the L2, as well as considering the pragmatic view of language. Furthermore, bearing in mind the nature of current reading models, we can now suggest a psycho-pragmatic model of reading, which is procedural and perfective, and of a pedagogical nature, that is, valid for the scenario of the focus of this study: students of English as a second language.

\section{- Components}

It consists of three main areas which overlap to form an area of intersection where comprehension is carried out by the L2 reader (figure 6):

a) The psycho-pragmatic elements (automatism of many basic processes, schemata, pragmatic factors, inferences, etc.).

b) The inherent interaction of all of them in the reading process, and

c) The pedagogical strategies to which readers are submitted in order to constantly improve understanding (adaptability of the schemata in the reader's socialization process to satisfy the requirements he has in order to be able to understand).

\section{- Aims}

\section{PSYCHO-PRAGMATIC MODEL}

a) To adapt the level of difficulty of the texts to the reader's level of understanding; texts can even be simplified provided that writing does not become artificial.

b) Get the students used to reading a group of words with a meaning, in one go, thus reinforcing the acquisition of automation of the bottom-up and top-down processes.

c) To practice reading speed both in looking for information and getting the general meaning of a text.

d) Get the students familiar with extra-textual elements that contribute to improving reading comprehension: illustrations, graphics and designs of publications.

e) Development of techniques that facilitate the acquisition of vocabulary: differentiation between categories of grammar, elaboration of functional schemata and induction of rules as well as new word formation systems.

f) To promote inference for the best explotation of grammatical and background knowledge to benefit comprehension.

g) To detect difficulties and typical errors in order to find appropriate methods of dealing with these. 


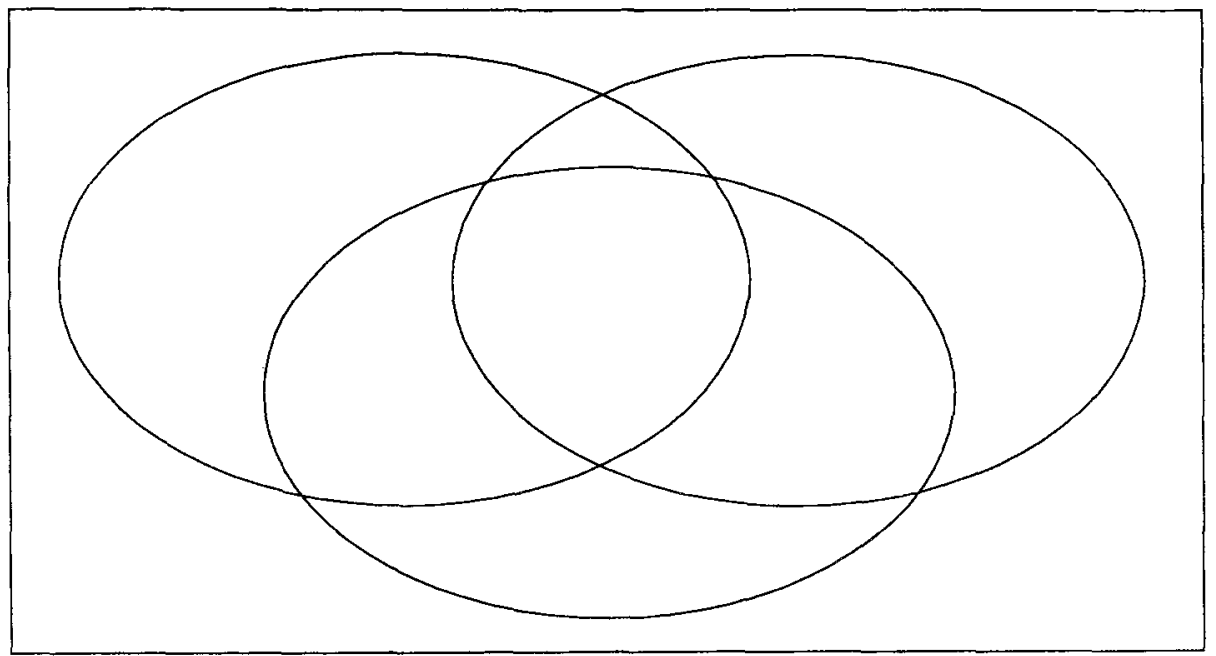

Figure 6

h) To give attention to the pragmatic environment surrounding the written discourse to enable better interpretation.

i) To train the L2 reader in both the practice of memory and the skills of summarising.

j) To train the reader in the use of tools that aid comprehension, especially the dictionary.

- Process

Every reader needs to know how both the grammar and vocabulary of a language are used, at least at a basic level, to understand how the fundamental concepts of language are expressed. He should also know that the communicative purpose of these concepts in academic writing determines the functions of language. And lastly, paragraphs and texts can be built by combining functions and concepts to produce an effect on the receiver, that is, the language being used, which constitutes the discourse.

With a group where reading is the predominant activity, any teacher has a wealth of knowledge and professional resources to carry out his task. This wealth should be turned into teaching activities to develop the comprehensive skills.

To solve the multiple problems that occur when these activities take place, a system of ideas is shown below, which will allow us to reach a practical conclusion: the selection of six groups of strategies through which the activities of the so-called psycho-pragmatic model will work. The first four will coincide in general terms with those of Nuttall (1982); the fifth one will answer the psycho-pragmatic and discourse issues already mentioned and the sixth one will relate to specific activities aimed at improving use of dictionaries and other reference works.

The model will function by putting these groups into action. They will be:

a) Strategies that deal with mode and speed in reading: skimming, scanning, extensive, intensive and study reading. 
b) Strategies that refer to extra-textual forms of information which are likely to be found in published works: photographs, graphics, diagrams, flowcharts, titles, headings, index, contents, references, bibliography, etc.

c) Strategies for understanding unknown words: identification of grammatical categories of the words and their morphology, practice in presuposition, inference, deduction and prediction, consultation of the teacher or fellow pupils.

d) Strategies to analyse text comprehension: activities which analyse its cohesion and coherence, study of common rhetorical structures, summaries, etc.

e) Strategies to analyse the pragmatic meaning of the texts, devising tasks to practise understanding discourse features.

f) Strategies to make the best use of the consultative sources available, such as dictionaries, grammar handbooks and monographs.

\section{Conclusion}

To the modern man, the search for and exchange of information through reading continues to be essential, in spite of the growing hegemony of audiovisual media.

Reading comprehension, which appears to be a simple phenomenon, is made up of multiple evanescent subprocesses that influence each other. The capacity of the human system is put to the test everytime mental resources are called upon to provide attention, consciousness and memory required for the purpose of reading. This is why reading models enable the existence and functioning of such subprocesses in the storing of information and providing of answers, which work in parallel and interactively.

To have a pattern taking account of all the mental processes activated when reading would be a panacea. Unfortunately, such a reading model does not exist, because those designed up to the present time are incomplete, as stated by their own authors.

This is why psychologists and linguists alike do not stop researching for formulae which provide explanations about which mental processes actually take part in reading and how they interact to produce the meaning of written discourse.

A summary of existing models has been presented in this article. They are in use nowadays. It is in addition to the findings of the researchers and current theory that we contribute the psycho-pragmatic model, designed to carry out the task of teaching, with the focus on students reading in the L2.

Bearing in mind the conditions that a good model should fulfil, the one we are proposing 'summarises the past' when trying to pinpoint the main features of the three most representative models of the last three decades. It underlines everything related to L2 reading as well as how the functioning of the different constituent processes of the models has been integrated in the interactive paradigm.

'Understanding of the present' is satisfied by providing the psycho-pragmatic, interactive and deontic components. The exercises suggested below are only a sample of how these three areas can be combined by the teacher to improve reading comprehension in practice, particularly in the academic field of ESP.

Finally, 'prediction of the future' can be carried out by its procedural and perfective nature. Given that the activities mentioned are being currently applied and can be subject 
to expansion, modification and improvements, we can presume that this type of model is guaranteed to survive into the future.

\section{Works cited}

Alcaraz, E. Tres Paradigmas de la Investigación Lingüística. Alcoy: Marfil,1990.

Balota, D., A. Pollatsek and K. Rayner. "The Interaction of Contextual Constraints and Parafoveal Visual Information in Reading." Cognitive Psychology, 17 (1985): 364-390.

Beaugrande, R. de \& W.U. Dressler. Introduction to Text Linguistics. (Longman Linguistic Library, 26). London: Longman, 1981.

Biber, D. "Spoken and Written Textual Dimensions in English: Resolving the Contradictory Findings." Language, 62 (1986): 384-414.

Black, M. Models and Metaphors. Nueva York: Cornell University Press, 1962.

Carrell, P.L. and J.C. Eisterhold. "Schema Theory and ESL Reading Pedagogy." TESOL Quarterly 18 (1983): 553-573 (1990 edition of Interactive approaches to Second Language Reading).

Carroll, J.B. Language and Thought. Englewood Cliffs, N.J.: Prentice-Hall, 1964.

Carver, R.P. "Toward a Theory of Reading Comprehension and Reading." Reading Research Quarterly, 13 (1977/78): 8-64.

Cattell, J.M. "The Time it Takes to See and Name Objects." Mind, 11 (1886): 63-65.

Chall, J. Stages of Reading Development. New York: McGrow-Hill Book Company, 1983

Darnton, R. "The Origins of Modern Reading." The New Republic 190-8 (1984): 26-33.

Eskey, D. "Theoretical Foundations." Teaching Second Language Reading for Academic Purposes. Eds. F. Dubin, D. Esley, and W. Grabe. Reading Mass.: Addison-Wesley, 1986. 3323.

Goodman, K.S. "A Psycholinguistic View of Reading Comprehension.” New Frontiers in CollegeAdult Reading (15th Yearbook of the National Reading Conference). Eds. G.B. Schick and M.M. May. Milwaukee, Wis.: National Reading Conference, 1966.

"Behind the Eye: What Happens in Reading." Reading: Process and Program. Eds.

K.S. Goodman and O.S. Niles. Urbana, Ill.: National Council of Teachers of English, 1970. "Analysis of Oral Reading Miscues: Applied Psycholinguistics." Psycholinguistics and Reading. Ed. F. Smith. New York: Holt Rinehart and Winston. 1970. 158-176.

Goodman, K.S. "Reading: a Psycholinguistic Guessing Game." In Theoretical models and processes of reading, 2 nd ed., Singer, H. \& Ruddell, R. (Eds.). Newark, Del.: International Reading Association, 1976 (first published in 1967).

"Letter to the Editor." Reading Research Quarterly 16 (1981): 477-478.

Gough, P.B. "One Second of Reading." Language by Ear and by Eye. Eds. J.F. Kavanagh and I.G. Mattingly. Cambridge, Mass.: MIT Press, 1972.

Grabe, W. "Reassessing the Term 'Interactive'." Interactive Approaches to Second Language Reading. Eds. P.L. Carrell, J. Devine and D.E. Eskey. Cambridge: Cambridge University Press, 1988 (1990 edition).

Holmes, The Substrata-Factor Theory of Reading. Berkeley: California Book, 1953.

Huey, E.B. The Psychology and Pedagogy of Reading. Cambridge, Mass.: MIT Press, 1968 (first published in 1908).

Javal, E. "Essai sur la Physiologie de la Lecture." Annales d'oculistique 82 (1879): 242-253. 
Just, M.A. and P.A. Carpenter. (1980): "A Theory of Reading: From Eye Fixations to Comprehension." Psychological Review 87- 4 (1980): 329-354.

Just, M.A. and P.A. Carpenter. The Psychology of Reading and Language Comprehension. Boston: Allyin and Bacon, Inc, 1987.

Kintsch, W. and T.A. Van Dijk. "Toward a Model of Text Comprehension and Production." Psychological Review 85 5 (1978): 363-394..

Kolers, P.A. "Three Stages of Reading." Basic Studies on Reading. Eds. H. Levin, H. and J.P. Williams. New York: Basic Books, 1970.

Laberge, D. Basic Processes in Reading: Perception and Comprehension. Hillsdale. N.J.: Lawrence Erlbaum Associates Publishers, 1977.

Meyer, D.E., R.W. Schvaneveldt and M.G. Ruddy. "Loci of Contextual Effects on Word Recognition." Attention and Performance. Eds. V. Rabbit, and S. Dornic. New York: Academic Press.

Miller, G.A., J.S. Bruner and L. Postman. "Familiarity of Letter Sequences and Tachistoscopic Identification." Journal of General Psychology 50 (1954): 129-139.

Moshental, P. "The Problem of Partial Specification in Translating Reading Research into Practice." Elementary School Journal 85 (1984): 199-227.

Nuttall, C. (1982): Teaching Reading Skills in a Foreign Language. London: Heinemann Educational Books, 1982 (edición 1985).

Ruddell, R.B. "Psycholinguistic Implications for a System of Communication Model." Psycholinguistics and the Teaching of Reading. Eds. K. Goodman.and J. Fleming. Newark, Del.: International Reading Association, 1969.

Rumelhart, D.E. "Toward an Interactive Model of Reading." Attention and Performance VI. Ed.

S. Dornic. Hillsdale, N.J.: Lawrence Erlbaum Associates, 1977.

Rumelhart, D.E. Human information processing. New York: Wiley, 1977.

Rumelhart, D.E. and J.L. "Interactive Processing Through Spreading Activation." Interactive processes in reading. Eds. M.A. Lesgold and C.D. Perfetti Hillsdale, N.J.: Lawrence Erlbaum Associates, 1981.

Samuels, S.J. and M.L. Kamil. "Model of the Reading Process." Interactive Approaches to Second Language Reading. Eds. P.L. Carrell, J. Devine and D.E. Eskey. Cambridge: Cambridge University Press, 1988. 20 (1990 edition).

Singer, H. "The Substrata-Factor Theory of Reading and its History and Conceptual Relationship to Interaction Theory." Reading Research Revisited. Eds. L. Gentiel, M. Kamil and J. Blanchard. Columbus, Oh.: Merrill, 1983.

Smith, F. Understanding Reading. New York: Holt, Rinehart and Winston, 1971.

Stanovich, K.E. "Toward an Interactive-Compensatory Model of Individual Differences in the Development of Reading Fluency." Reading Research Quarterly 16 (1980): 32-71.

Stanovich, K.E. "The Interactive-Compensatory Model of Reading: A Confluence of Developmental, Experimental, and Educational Psychology." Remedial and Special Education 5 (1984): 11-19.

Taylor, I. and M. Taylor. The Psychology of Reading. New York: Academic Press, 1983.

Tulving, E. and C. Gold. "Stimulus Information and Contextual Information as Determinants of Tachistoscopic Recognition of Words." Journal of Experimental Psychology 66 (1963): 319327.

Weber, R.M. "First Graders' Use of Grammatical Context in Reading." Basic Studies on Reading. Eds. H. Levin, and J.P. Williams. New York: Basic Books, 1970. 
Widdowson, H.G. "The Process and Purpose of Reading." Explorations in Applied Linguistics. Oxford: Oxford University Press, 1979. 